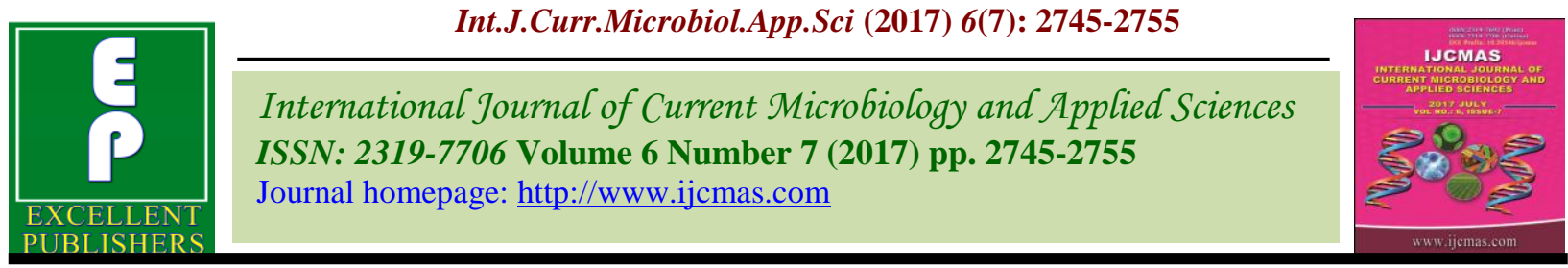

Original Research Article

https://doi.org/10.20546/ijcmas.2017.607.385

\title{
Product Characterization of Thirattupal - A Traditional Sweet Product of Tamil Nadu, India
}

\author{
Harin Sutariya*, K. Jayaraj Rao, Ravi Chauhan, Nancy Talwar and Diwakar Mishra \\ Dairy Technology Section, Southern Regional Station, \\ ICAR- National Dairy Research Institute, Adugodi, Bengaluru, India \\ *Corresponding author
}

\begin{abstract}
A B S T R A C T
Thirattupal is a traditional milk sweet of Tamil Nadu. Its physico-chemical, sensory, microbial and textural quality attributes have been studied and characterized. Samples were collected from three cities viz. Chennai, Coimbatore and Madurai which are known

Keywords

Characterization,

Thirattupal, Tamil

Nadu, Traditional product.

Article Info

Accepted:

29 June 2017

Available Online:

10 July 2017

for Thirattupal preparation and home for well-known Thirattupal manufacturers, and the quality attributes were recorded and documented. The best acceptable attributes which are typical to Thirattupal have been decided as the typical characteristics of Thirattupal. Wide variations in the composition of the market samples existed. Moisture, fat, protein, lactose, sucrose, ash, acidity and free fatty acids contents of the market samples were in the range of $16.68-23.94,13.41-19.94,12.57-16.00,12.81-16.55,36.09-41.48,1.74-2.33,0.37-0.44$ and 10.58-13.39\%, respectively. Ranges of sensory scores, instrumentally evaluated textural and colour characteristics have been recorded. Microbial analysis showed moderate standard plate counts (SPC), coliform, yeast and mould counts in market samples of Thirattupal. Sensory attributes of highly preferred Thirattupal sample were: light brown to medium brown colour, granular and firm body with uniformly distributed medium soft grains, pleasant nutty and caramelized flavor with added cardamom flavour. This overall characterization of Thirattupal will help in any further works to be taken up on Thirattupal for example cottage level manufacture, mechanization etc.
\end{abstract}

\section{Introduction}

In India, a large variety of traditional sweets are manufactured and consumed and the basic ingredient of most of these traditional sweets is either cow milk or buffalo milk. Many traditional dairy products in India, which were hitherto unknown, have been identified and characterized. Many products still remain confined to local regions which are not yet known in other parts of the country. These products form part of country's rich cultural heritage and there is a need to bring these products into light and make others known about these products. Aided by today's communication technologies, several recipes can be found on www, however, since much of our population is beyond the reach of internet, such information has not yet percolated down the line among consumers. Several products have their origin in specific areas like Mysore pak (Mysore), Dharwad peda (Dharwad), Mathura peda (Mathura), kunda (Belgaum), basundi, khoa jalebi and shrikhand (Maharashtra), payasam (Karnataka and Kerala) etc. Similarly, Thirattupal also 
called as Thirattipal, is a popular traditional dairy product which has its origin in Tamil Nadu state of India. In Tamil language, 'Thirattu' means continuous stirring to concentrate the ingredients and 'pal' means milk. It is obtained by partial coagulation of milk by addition of one or two spoons of sour curd prior to addition of sugar and completion of desiccation. It is specially used for celebrating occasions like engagement ceremony, wedding function and 'gruhpravesham'. Popularity of this indigenous product is confined to specific region. The composition of the product available in market varies widely due to lack of any set quality standards. Varying manufacturing practices, ingredient quantity and quality and the storage temperature of the final product are major reasons behind wide variations in the composition. Also, information on the aspects pertaining to the standard quality product of Thirattupal and its characteristics is not available till date. Thus, defining the product with its characteristic features is an important criterion to evaluate the product precisely and specifically. Prerequisite for such efforts is product characterization through suitable techniques like survey works, earlier reported by several workers to characterize traditional products such aspeda (Ray et al., 2002, Rasane and Jha, 2012 and Banjare et al., 2015 burfi (Ghodekar et al., 1980 and Shete et al., 2012) kalakand (Arora et al., 1991, Moulick et al., 1996), kunda (Kulkarni et al., 2001), dodaburfi (Chawla et al., 2011), thabdi (Patel et al., 2012), halvasan (Patel et al., 2010), khoajalebi (Jayaraj and Pagote, 2012) and kheer mohan (Meena et al., 2014). Such studies are mainly conducted to understand, define and differentiate between unique and typical attributes of indigenous dairy products. Outcomes of such studies serve two important functions viz. they act as a base platform for the future research and development activities and they add a new item to the products portfolio of organized dairy sector.

\section{Materials and Methods}

\section{Collection of thirattupal samples}

Thirattupal is prepared in many households in Tamil Nadu. It is also being sold in various sweet shop outlets in towns and cities. Through various sources and media, well known manufacturers of Thirattupal were identified. Samples of Thirattupal were procured from selected cities namely Chennai (C-1), Coimbatore (C-2) and Madurai (C-3). These cities were more preferred because Thirattupal is well known in these regions and manufacturing of Thirattupal is more practiced over here. As good numbers of product manufacturing units were present in these cities, they were able to meet local market demand as well as supply this product to nearby regions too. Information pertaining to product's typical attributes was collected using pre-designed questionnaires and face to face interaction with several halwais, shopkeepers and consumers. Available facilities and use of ingredients at the manufacturer's door were seen and recorded. Based on this record, a few selected samples from well-known manufactures were brought to Southern Regional Station of ICAR-NDRI in their packaging containers, in triplicate, and evaluated for sensory, textural, microbial and physico-chemical parameters.

\section{Proximate composition}

The market samples of Thirattupal were thoroughly mixed using pestle and mortar and the homogeneous mass was used for all the analyses. However, for textural analysis, it was used 'as it is'. The following physicchemical estimations were made by the methods mentioned: moisture content gravimetric method (BIS, 1981), fat content- 
Mojonnier method (AOAC, 2005), ash content - gravimetric method (AOAC, 2005), total protein - Kjeldahl method (AOAC, 2005), lactoseand sucrose - volumetric method (BIS, 1981), titrable acidity titrimetric method (BIS, 1981), FFA - method of Deeth et al., (1975) and colour by Yam and Papadakis (2004).

\section{Texture profile analysis}

Texture profile analysis of the samples of Thirattupal was carried out using Texture Analyzer, TA.XT plus Stable Micro System, England. The $\mathrm{p} / 75$ probe of the instrument was used for the estimation. The instrument test settings of TA.XT plus instrument were as follows: test mode: compression, pre-test speed: $1 \mathrm{~mm} / \mathrm{s}$, test speed: $5 \mathrm{~mm} / \mathrm{s}$, post-test speed: $5 \mathrm{~mm} / \mathrm{s}$, target mode: distance, distance: $10 \mathrm{~mm}$, time: $5 \mathrm{sec}$, trigger type: auto (force),trigger force: $5 \mathrm{~g}$, break Mode: off, advanced option: on. After loading the test settings, the probe was calibrated to a distance of $50 \mathrm{~mm}$, above the surface of platform on which sample was to be kept. Thirattupal sample, gently patted into cubes of $20 \times 20 \times 20 \mathrm{~mm}$ and tempered at $30 \mathrm{oC}$ for about an hour, was kept positioned centrally over the platform and the computer was allowed to execute the program to run the test, then the sample was compressed by the plunger twice (resembling two bites) and the force exerted back by the sample onto the plunger was sensed by the machine generating a two peak force - time curve (Fig. 1). Different textural parameters like cohesiveness, gumminess, springiness and chewiness were estimated form the force-time graph.

\section{Sensory evaluation}

Sensory evaluation of the screened Thirattupal samples was carried out by semitrained faculty of Dairy Technology Section,
ICAR-NDRI (SRS), Bengaluru using 9-point hedonic scale and descriptive sensory evaluation (DSE) technique, in an hygienic and well ventilated laboratory. The judges were asked to evaluate and describe various product attributes viz. colour and appearance, flavour, body and texture, sweetness and overall acceptability.

\section{Microbiological analysis}

All the market samples of Thirattupal were analyzed for standard plate count (SPC), coliform count and yeast and mould count by BIS (2002), BIS (2002) and BIS (1999) methods, respectively.

\section{Statistical analysis}

Data obtained for Thirattupal samples were statistically analyzed employing one way ANOVA using SPSS software, to know the variations in samples between markets as well as within the markets.

\section{Results and Discussion}

\section{Physico chemical attributes of thirattupal}

The compositional attributes of Thirattupal (i.e. moisture, fat, protein, lactose, sucrose and acidity) between the markets were statistically significant $(\mathrm{p}<0.05)$ as shown in table 1 .

\section{Moisture}

The moisture content of Thirattupal samples collected from different cities ranged from 16.68-23.94\%. The traditional Thirattupal makers determine the final consistency with experience to obtain a product with moisture content which may vary within a narrow range. However, some manufacturers prefer relatively low or high moisture in their product that may be because of market 
preferences for such products. The variation in the moisture content of Thirattupal among manufacturers within particular city may be due to slight differences in their manufacturing techniques, composition of raw milk and the marketing requirements. Further, the lower or higher moisture content in a particular sample might be responsible for its higher or lower storage life. Rao and Goyal (2007) reported moisture content in kalakand to be $25.14 \%$ which was a bit higher as compared to that of Thirattupal. Shete et al., (2012) found that market samples of burfi had moisture content of 17.10 to 25.87. Banjare et al., (2015) reported moisture of peda in range of 12.22 to $23.34 \%$.

\section{Fat}

Fat constitutes an important component in Thirattupal. It not only influences the flavor and textural properties of Thirattupal, but also contributes significantly to its nutritional, calorific value and most importantly its cost. Milk fat has a pleasant flavor because of presence of butyric and other small chain fatty acids (Park and Haenlein, 2013). Further, free fat also oozes out during manufacture just like in other khoa based sweets. The range for fat content of Thirattupal samples collected from markets was 13.41-19.94\%. The values obtained for fat within the city showed variations. The fat content obtained in Thirattupal was comparable to the fat content found in the various other heat desiccated dairy products such as peda, burfi, kalakand, and kunda and milk cake. Fat content depends on the initial fat content of milk used for product preparation. As per the interaction with the manufacturers, milk was not standardized before using for Thirattupal manufacture. This is because, the manufacturers are only concerned with manufacture of product which satisfies consumers and not producing best quality product which will have maximum consumer acceptance. This can be understood because the manufacturers have to keep in mind cost component also which is a main determinant factor in consumer acceptance of the product. Several researchers reported wide variation in fat content of traditional dairy products collected from different markets. Kulkarni et al., (2001) observed wide variation in fat contents (5.1-17.2) of market sample of kunda. Shete et al., (2012) reported 10.05 to $18.02 \%$ of fat in market samples of burfi. Banjare et al., (2015) also found wide variation in fat contents (12.26 to 22.58) of peda samples collected from Raipur.

\section{Protein}

The protein content in Thirattupal is one of the most important constituents which exert direct as well as indirect influence on textural or rheological properties of Thirattupal. It also contributes to calorific value and hence is important from the nutritional point of view. It acts as a continuous matrix in which other constituents are embedded. The coagulated protein particles are quoted with molten sugar and free fat. Thus when chewed in mouth, sugar and free fat are released giving a relishing taste. The range for protein content of Thirattupal samples collected different cities was 12.57-16.00\%.Ray et al., (2002) collected peda samples from Kolkata market which had protein content in range of 15.2616.79. Kulkarni et al., (2001) reported wide variation in protein contents (5.9-11.3) of market samples of kunda. Shete et al., (2012) found protein content varied from 7.94 to 16.01 in market samples of burfi.

\section{Lactose}

Lactose content plays an important role in the taste and colour of Thirattupal. It contributes to the sweetening of milk products and at the same time influences the colour and appearance of the products when it is 
manufactured employing heat. It is well established that this change occurring as a result of caramelization also imparts cooked, nutty flavour to the end product and hence lactose content and its status in the sweets prepared are very important. Maillard reaction between lactose and proteins causes browning colour of Thirattupal. The caramelization of lactose also contributes to the typical nutty flavor of Thirattupal. The range for lactose content of Thirattupal samples was 12.81$16.55 \%$. This variation may be attribute to inherent variations of lactose in milk as well as the extent of desiccation during manufacturing. Ray et al., (2002) observed lactose content in peda collected from Kolkata as 12.96-15.83\%. Rao and Goyal (2007) reported kalakand with $18.01 \%$ lactose. Kulkarni et al., (2001) reported wide variation in lactose contents (1.9-15.9) of market samples of Kunda. From this discussion, it can be inferred that different manufacturers in different cities use different types of milks for sweets making which can be reflected in the final compositional constituents such as lactose. Any adulterated raw milk can also give variations in the lactose content.

\section{Sucrose}

Sucrose acts as a source of profit or overrun in sweets, because it is cheaper than milk constituents. Higher the sugar content, higher is the profitability. This is the reason why many sweets have profitability up to $30 \%$. As such high variations can be expected in sugar content in market samples. However, at higher levels of sugar, the product is too sweet deterring many consumers from consuming it, especially health conscious consumers. Sugar though does not participate in Maillard reactions, it aids in colour development by means of sugar caramelization which also adds to the flavor of the product in presence of uncaramelized sugar. Sugar added as a sweetener decides the consumer's acceptance or rejection to a great extent by fulfilling the eating qualities, textural properties and colour development by way of caramelization during desiccation apart from helping as a natural preservative to enhance the keeping quality of indigenous milk sweets. Sucrose also plays an important role in pricing of milk sweets. Thus, it is a very important constituent of milk sweets. Sucrose content of market samples of Thirattupal ranged from 36.09 to 41.48 . Ray et al., (2002) reported sucrose content in peda to be 13.2 to $61.8 \%$, which is a very high range of variation as compared to that observed in Thirattupal because peda were manufactured employing several variables which gave wide variation in their values. Kulkarni et al., (2001) reported very high variation in sucrose contents (25.6-51.21) of market samples of Kunda. Thus it can be seen that very wide variations in the sucrose levels exist in the market samples of other sweets. However, though Thirattupal samples from market in the present study differed, the differences were narrow as compared to such other sweets in the market.

\section{Ash}

The ash content in milk products is the measure of their inorganic mineral contents. It does not vary much. Milk sweets are added with some nuts, which also contribute to the mineral contents of the products. The range of ash content in Thirattupal samples was 1.74$2.33 \%$. Even in other dairy products not much variation is reported. Ray et al., (2002) reported wide variations in ash content of market peda which was in the range of 1.8 $2.87 \%$. Moulick et al., (1996) reported 1.64 $3.16 \%$ ash in kalakand made from either cow milk or buffalo milk. Rao and Goyal (2007) found ash content in kalakand in the similar range. 


\section{Acidity}

The titratable acidity (expressed as per cent lactic acid) is an important deteriorative chemical change which can occur in Thirattupal like in any other milk sweet. The level of acidity produced may also be an indicator to the extent of microbial fermentation. The drastic change in acidity may even influence the consumers' acceptability of the product too.

The range for acidity of Thirattupal samples collected from different cities was 0.37 to $0.44 \%$ (LA). The variation in the acidity of Thirattupal among manufacturers within the cities may be the result of use of either the milk with different acidity or use of stored milk for manufacture of Thirattupal. In comparison to other milk sweets, the acidity value seems to be within the range. This is because fresh samples from the market were collected. During storage the acidity of the samples is expected to increase because of yeast and mould growth. Further, sugar caramelization is supposed to release acidic compounds. Acidity of as low as $0.07 \%$ and as high as $0.74 \%$ have been reported in peda from Kolkata market by Ray et al., (2002).This may be because stored samples might have been collected during survey work. Banjare et al., (2015) also observed wide variation in acidity of peda (0.37 $0.63 \%)$.

\section{Free fatty acids (FFA)}

Free fatty acids (FFA) $(\mu \mathrm{eq} / \mathrm{gm})$ are the measure of lipolysis because of processing or any type of fat degradation occurring in the product prior to or after manufacturing. It may impart oily flavour and also may be responsible for the development of rancidity. The reason for increase in FFA may be that lipases released by microorganisms or those existed in milk and survived processing conditions, might have acted on the fats and released FFA. The milk used for Thirattupal making might have been infested with lipases released by psychrotrophs which are known to produce lipases which are highly heat resistant. There are reports of release of FFA even by intense heat processing conditions like desiccation, scraping and agitation, though it requires further study.

The average range for FFA of Thirattupal samples collected was $10.58-13.39 \mu \mathrm{eq} / \mathrm{gm}$ which is a narrow range. Ray et al., (2002) found peda samples from Kolkata market as having free fatty acid in the range of $0.056-$ 0.65 (\% oleic acid). Moulick et al., (1996) reported kalakand samples as having free fatty acid (as \% oleic acid) ranging from $0.052-0.108$ free fatty acids (as per cent oleic acid).

\section{Sensory quality of market samples of Thirattupal}

The scores of sensory attributes such as colour and appearance, body and texture, flavour and overall acceptability of Thirattupal collected from different cities are delineated in table 2 . The sensory attributes have profound effect on the consumers' preference. These attributes are the result of compositional constituents and the processing methodology employed for particular product manufacturing. The wide range in values of color and appearance score of samples collected from each city clearly revealed shop to shop variation. This may be due to lack of proper care during preparation and poor packaging materials which may result in undesirable visual appearance. In the present study, some the of the observations were also recorded by judges which included dry and dull appearance, medium brown to dark brown color, creamy white color, glossy and granular appearance. Similar variations were reported by Patel (1996) for market peda and 
Londhe (2006) for brown peda. Anon. (2006) reported that kunda sold in market varied from semi-brown to brown color indicating variations in market samples. The wide range in values of body and texture score of samples collected from each city could be mainly attributed to variation in moisture content. In the present study, judges described Thirattupal as having pasty, chewy body with small to medium grains and granular texture. The wide range in values of flavour score of samples collected from each city clearly revealed shop to shop variation. This may be due variation in preparation method and chemical composition of particularly fat and sugar levels in the final product. In the present study, some of the observations described by sensory judges included pleasant sweet, caramelized, nutty flavour with added cardamom.

\section{Textural attributes of market samples of Thirattupal}

Since the texture is important factor of Thirattupal, it contributes to deciding of acceptance by the consumers. The texture profile parameters viz. hardness, springiness, adhesiveness, cohesiveness, chewiness and gumminess were measured using Texture Analyzer. The mean scores of hardness, springiness, adhesiveness, cohesiveness, chewiness and gumminess of Thirattupal collected from different cities are delineated in table 3 . Wide variations within and among the manufactures as well as cities were observed for the textural parameters of market samples of Thirattupal. The average ranges for hardness, springiness, adhesiveness, cohesiveness, chewiness and gumminess of the Thirattupal samples were 4.93-7.91 N, 0.09-0.35, 0.13-0.54 N.sec, 0.1-0.23, 0.06$0.40 \mathrm{~N}$ and $0.71-1.44 \mathrm{~N}$, respectively. The wide range in values of hardness of samples collected from each city was due to variation in moisture, fat and sucrose content of the Thirattupal. Murtaza et al., (2017) reported that fat and moisture play a major role in textural attributes of dairy products. Patelet al., (1990) also reported that the moisture content of peda had direct relationship to hardness. Lower chewiness (1.2 N.mm) and very high gumminess $(28.6 \mathrm{~N})$ in plain peda prepared by traditional method was also reported by Patel (1996). Banjare et al., (2015) observed during textural studies of market and laboratory made peda samples which revealed that hardness, adhesiveness, cohesiveness, springiness, gumminess and chewiness as ranging from 397.50 to $3417.71 \mathrm{~g},-70.15$ to -1.38 g.s, 0.094 to 0.159 , 0.12 to $0.20 \mathrm{~mm}, 13.08$ to $385.41 \mathrm{~g}$ and 1.53 to 53.43 g.mm respectively.

\section{Color parameters of market samples of Thirattupal}

The colour parameter is an important factor of Thirattupal which decide the extent of heating. Though colour quality is judges by visual observation, the same may be quantified by Adobe Photoshop method. Colour values $\mathrm{L}^{*}, \mathrm{a}^{*}$ and $\mathrm{b}^{*}$ values of Thirattupal samples ranged from 65.09 (C-1) 86.56 (C-3), $6.33-15.33$ and 32.80- 43.27, respectively (Table 4). It can be inferred from average values of $\mathrm{L}^{*}$ that city $\mathrm{C}-1$ had most dark color and city C-3 had most white color. The wide variation in values of $\mathrm{L}^{*}$ of samples collected from each city was due to variation in extent of heating, level of sugar addition and heat interaction between sugar and milk constituents, all of which reflected as browning.

\section{Microbiological quality of market samples of Thirattupal}

Results of microbial analysis of the Thirattupal samples have been presented in table 5. There was significant difference found in SPC of samples collected from different cities. 
Table.1 Compositional attributes of Thirattupal samples collected from three cities in Tamil Nadu

\begin{tabular}{|c|c|c|c|c|}
\hline \multirow{2}{*}{$\begin{array}{c}\text { Physico-chemical } \\
\text { attribute }\end{array}$} & Range & C-1 & C-2 & C-3 \\
\cline { 3 - 5 } & $16.68-23.94$ & $18.59 \pm 1.91^{\mathrm{b}}$ & $21.38 \pm 2.56^{\mathrm{a}}$ & $19.47 \pm 2.22^{\mathrm{b}}$ \\
\hline \%Moisture & $13.41-19.94$ & $17.78 \pm 1.79^{\mathrm{a}}$ & $15.06 \pm 1.65^{\mathrm{b}}$ & $18.01 \pm 1.93^{\mathrm{a}}$ \\
\hline \%Fat & $12.57-16.00$ & $15.01 \pm 0.99^{\mathrm{a}}$ & $13.28 \pm 0.71^{\mathrm{b}}$ & $14.42 \pm 0.95^{\mathrm{a}}$ \\
\hline \%Protein & $12.81-16.55$ & $13.89 \pm 1.08^{\mathrm{b}}$ & $15.06 \pm 0.08^{\mathrm{a}}$ & $15.58 \pm 0.97^{\mathrm{a}}$ \\
\hline \%Lactose & $36.09-41.48$ & $39.72 \pm 1.76^{\mathrm{b}}$ & $37.41 \pm 1.32^{\mathrm{a}}$ & $37.67 \pm 1.12^{\mathrm{a}}$ \\
\hline \%Sucrose & $1.74-2.33$ & $2.05 \pm 0.28$ & $1.99 \pm 0.17$ & $1.91 \pm 0.17$ \\
\hline \%Ash & $0.37-0.44$ & $0.42 \pm 0.02^{\mathrm{a}}$ & $0.39 \pm .02^{\mathrm{b}}$ & $0.41 \pm 0.03^{\mathrm{ab}}$ \\
\hline $\begin{array}{c}\text { Acidity (\%l.a.) } \\
\text { \% Free fatty acids } \\
(\mu \text { eq/gm) }\end{array}$ & $10.58-13.39$ & $12.05 \pm 1.34$ & $11.57 \pm 0.76$ & $11.14 \pm 0.56$ \\
\hline
\end{tabular}

${ }^{\mathrm{ab}}$ mean values within a row with different superscripts are significantly different $(\mathrm{p}<0.05), \mathrm{n}=3$

Table.2 Sensory Attributes of Thirattupal samples collected from three cities in Tamil Nadu

\begin{tabular}{|c|c|c|c|c|}
\hline \multirow{2}{*}{ Sensory attribute } & \multirow{2}{*}{ Range } & \multicolumn{3}{|c|}{ City } \\
\cline { 3 - 5 } & & $\mathbf{C - 1}$ & $\mathbf{C - 2}$ & $\mathbf{C - 3}$ \\
\hline Color and appearance & $7.08-8.01$ & $7.75 \pm 0.26^{\mathrm{a}}$ & $7.49 \pm 0.41^{\mathrm{b}}$ & $7.68 \pm 0.33^{\mathrm{a}}$ \\
\hline Body and texture & $6.91-8.10$ & $7.65 \pm 0.44^{\mathrm{a}}$ & $7.41 \pm 0.49^{\mathrm{b}}$ & $7.65 \pm 0.37^{\mathrm{a}}$ \\
\hline Flavour & $6.80-8.06$ & $7.74 \pm 0.32^{\mathrm{a}}$ & $7.37 \pm 0.57^{\mathrm{b}}$ & $7.65 \pm 0.31^{\mathrm{a}}$ \\
\hline Overall acceptability & $6.91-8.01$ & $7.73 \pm 0.27^{\mathrm{a}}$ & $7.40 \pm 0.49^{\mathrm{b}}$ & $7.67 \pm 0.32^{\mathrm{a}}$ \\
\hline
\end{tabular}

${ }^{\mathrm{ab}}$ mean values within a row with different superscripts are significantly different $(\mathrm{p}<0.05), \mathrm{n}=3$

Table.3 Textural attributes of Thirattupal samples collected from three cities in Tamil Nadu

\begin{tabular}{|c|c|c|c|c|}
\hline \multirow{2}{*}{ Textural attribute } & \multirow{2}{*}{ Range } & \multicolumn{3}{|c|}{ City } \\
\cline { 3 - 5 } & & C-1 & C-2 & C-3 \\
\hline Hardness(N) & $4.93-7.91$ & $6.63 \pm 1.28^{\mathrm{a}}$ & $5.86 \pm 0.38^{\mathrm{ab}}$ & $5.54 \pm 0.61^{\mathrm{b}}$ \\
\hline Springiness & $0.09-0.35$ & $0.18 \pm 0.09^{\mathrm{b}}$ & $0.23 \pm 0.06^{\mathrm{ab}}$ & $0.27 \pm 0.08^{\mathrm{a}}$ \\
\hline Adhesiveness(N.sec) & $0.13-0.54$ & $0.32 \pm 0.19$ & $0.37 \pm 0.17$ & $0.34 \pm 0.18$ \\
\hline Cohesiveness & $0.1-0.23$ & $0.16 \pm 0.06$ & $0.17 \pm 0.06$ & $0.16 \pm 0.05$ \\
\hline Chewiness(N) & $0.06-0.40$ & $0.19 \pm 0.13$ & $0.25 \pm 0.15$ & $0.26 \pm 0.14$ \\
\hline Gumminess(N) & $0.71-1.44$ & $1.06 \pm 0.28$ & $1.06 \pm 0.38$ & $0.93 \pm 0.22$ \\
\hline
\end{tabular}

${ }^{\mathrm{ab}}$ mean values within a row with different superscripts are significantly different $(\mathrm{p}<0.05), \mathrm{n}=3$ 
Table.4 Color parameters of Thirattupal samples collected from three cities in Tamil Nadu

\begin{tabular}{|c|c|c|c|c|}
\hline \multirow{2}{*}{$\begin{array}{c}\text { Colour } \\
\text { Attribute }\end{array}$} & Range & \multicolumn{3}{|c|}{ City } \\
\cline { 3 - 5 } & $65.09-86.56$ & $72.91 \pm 7.12$ & $75.39 \pm 10.30$ & $76.21 \pm 10.35$ \\
\hline $\mathrm{L}^{*}$ & $6.33-15.33$ & $12.30 \pm 2.53$ & $10.99 \pm 3.73$ & $10.83 \pm 4.50$ \\
\hline $\mathrm{a}^{*}$ & $32.80-43.27$ & $40.29 \pm 1.25^{\mathrm{a}}$ & $40.21 \pm 3.06^{\mathrm{a}}$ & $35.98 \pm 3.18^{\mathrm{b}}$ \\
\hline $\mathrm{b}^{*}$ & &
\end{tabular}

${ }^{\mathrm{ab}}$ mean values within a row with different superscripts are significantly different $(\mathrm{p}<0.05), \mathrm{n}=3$

Table.5 Microbiological quality of Thirattupal samples collected from three cities in Tamil Nadu

\begin{tabular}{|c|c|c|c|c|}
\hline \multirow{2}{*}{$\begin{array}{c}\text { Microbiological } \\
\text { attribute }\end{array}$} & Range & \multicolumn{3}{|c|}{ City } \\
\cline { 3 - 5 } & $5.34-6.28$ & $5.65 \pm 0.31^{\mathrm{b}}$ & $\mathbf{C - 2}$ & $\mathbf{C - 3}$ \\
\hline SPC & $1.55-2.67$ & $2.16 \pm 0.51$ & $1.99 \pm 0.19^{\mathrm{a}}$ & $6.11 \pm 0.17^{\mathrm{a}}$ \\
\hline Coliform & $1.22-3.26$ & $2.24 \pm 1.02$ & $2.24 \pm 0.11$ & $1.92 \pm 0.06$ \\
\hline Yeast and mould & 1.22 & $1.84 \pm 0.08$ \\
\hline
\end{tabular}

${ }^{\text {ab }}$ mean values within a row with different superscripts are significantly different $(\mathrm{p}<0.05), \mathrm{n}=3$

Fig.1 A typical force-deformation curve for double cycled compression

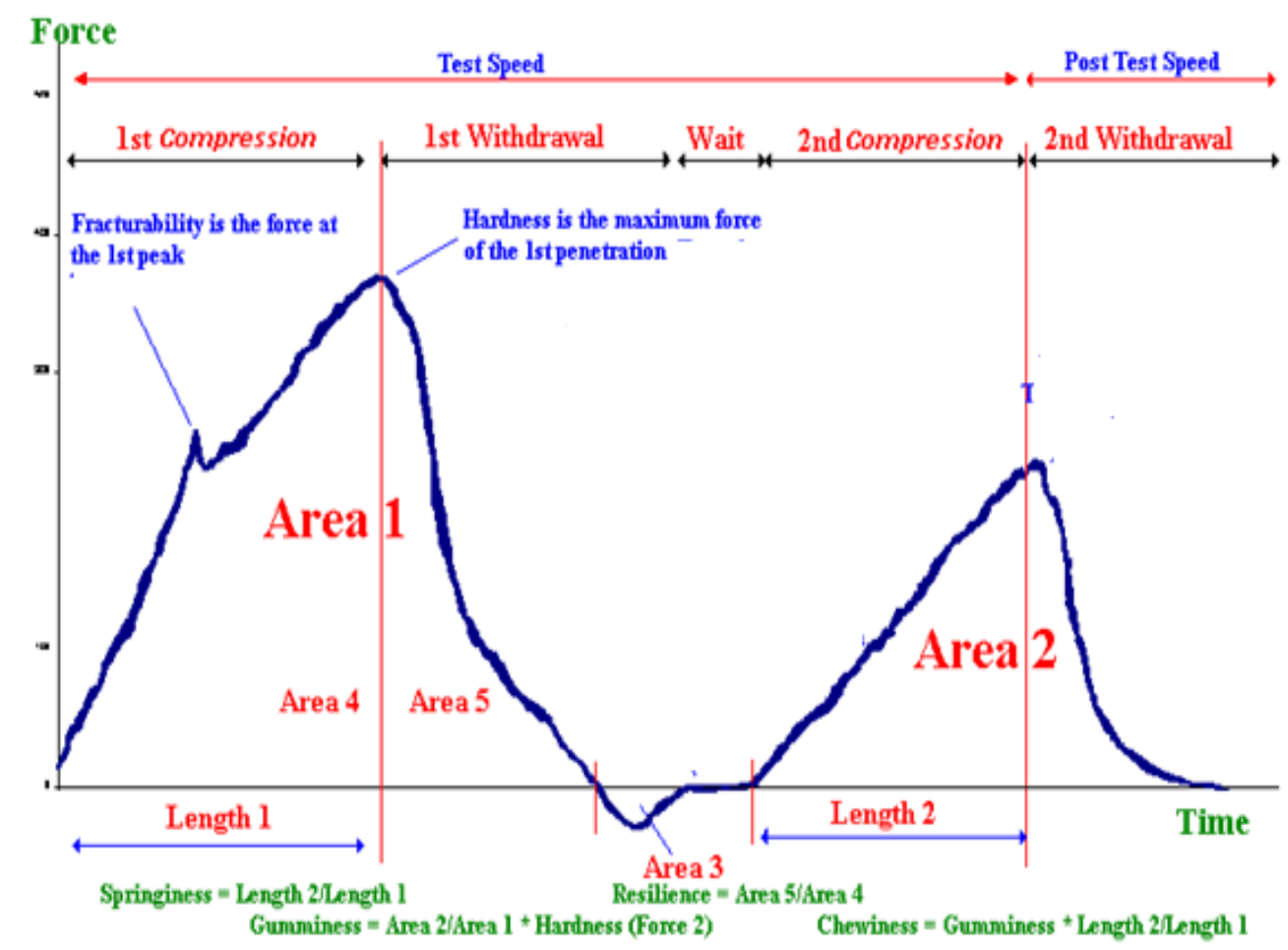

The poor hygienic practices employed during processing and handling with chances of post processing contamination. Similar findings have been reported by Singh et al., (1975),
Dwarkanath and Srikanta (1977) and Garg and Mandokhot (1984). Though TBC showed presence of bacteria, these are not expected to grow and cause spoilage because of low 
moisture and high sugar content. It is known that few bacteria grow below water activity of 0.90. Thirattupal is expected to have water activity below 0.90 . Thus, it is understood that only yeasts and molds can grow under Thirattupal environment and cause spoilage.

In conclusion, thirattupal samples collected from different cities of Tamil Nadu showed wide variations in their physico-chemical and textural attributes. Presence of higher SPC, yeast and mold and coliform counts in market samples indicated the lack of proper hygienic practices adopted for preparation and handling of the product. Based on the observations of sensory panel, typical characteristics of Thirattupal should be light brown to medium brown in colour with slight free fat appearance, granular texture with soft grains and caramelized flavour with added cardamom. The survey of the market also indicated that different methods were adopted by halwais in the preparation of Thirattupal. Results obtained during the present investigation are of great importance in determination of product quality. To add a new item in the food basket of the global consumers with uniform quality and improved safety, large scale production and marketing of this product can be taken up by organized sector. Consequently, optimization of process parameters will act as a pre-requisite to showcase this product as a typical Indian traditional product in various forums.

\section{Acknowledgement}

Authors express sincere thank Head, Southern Regional Station and In-charge Dairy Technology Section for help in all aspects of the project and in conducting experimental trials. The first author gratefully acknowledges the financial assistance received from ICAR-NDRI, Karnal (Deemed University), and University Grant Commission, India for carrying out the present study.

\section{References}

Anon. 2006. Research and development support for process up-gradation of indigenous milk products for industrial application. Network Project Report, NDRI (Southern Campus), Bangalore.

AOAC. 2005. Official methods of analysis of AOAC international, $18^{\text {th }}$ Ed., Washington D.C.

Arora, K.L., Chander, H. and Ram, J. 1991. Chemical and microbiological quality of kalakand sold in the market. Asian J. Dairy Res., 10: 96-02.

Banjare, K., Kumar, M. and Goel, B.K. 2015. Effect of storage on chemical, textural and sensory attributes of traditional indigenous sweet peda. Asian J. Dairy Food Res., 34(2): 104-108.

Banjare, K., Kumar, M., Goel, B.K. and Uprit, S. 2015. Studies on chemical, textural and sensory characteristics of market and laboratory peda samples manufactured in Raipur city of Chhattisgarh. Oriental $J$. Chem., 31(1): 231-238.

BIS. 1981. IS: SP: 18 ISI Handbook of food analysis. (Part XI). Dairy products. Indian Standard Institution, Manak Bhavan, New Delhi.

BIS. 1999. IS: 5403 Methods for Yeast and Mold count of foodstuffs and animal feeds, Bureau of Indian Standards, Manak Bhavan, New Delhi.

BIS. 2002. IS: 5401 General Guidance for the enumeration of coliforms (Part I), Bureau of Indian Standards, Manak Bhavan, New Delhi.

BIS. 2002. IS: 5402 General Guidance for the enumeration of micro-organism, Bureau of Indian Standards, Manak Bhavan, New Delhi.

Chawla, R., Patil, G.R. and Singh, A.K. 2011. Physicochemical and textural attributes of market sample of Dodaburfi. Dairy Foods Int., 1(1): 176-83.

Deeth, H.C., Fitx-Gerald, C.H. and Wood, A.F. 1975 A convenient method for determining extent of lipolysis in milk. Aust. J. Dairy Technol., 30(3): 109-111.

Dwarkanath, C.T. and Srikanta, S. 1977. Studies on the microbiological quality of traditional 
Indian sweet meat products. J. Food Sci. Technol., 14: 201-204.

Garg, S.R. and Mandokhot, U.V. 1984. Studies on microbial and chemical profile of some Indian sweet meats and their significance. Indian J. Dairy Sci., 37(4): 326-333.

Ghodekar, D.R., Rangnathan, B. and Dudani, A.T. 1980. Yeasts and moulds in indigenous milk products. Indian J. Dairy Sci., 33(2): 255-259.

Jayaraj, R.K. and Pagote, C.N. 2012. Khoa Jalebi, a unique traditional product of central India. Indian J. Tradi. Knowledge, 11(1): 96-102.

Kulkarni, S., Ghosh, B.C., Balasubramanyam, B.V. and Rao, K.J. 2001 Kunda-desiccated dairy product of northern Karnataka. Indian Dairyman, 53(11): 65-68.

Londhe, G.K. 2006. Development of a process for manufacture and shelf life extension of brown peda. Ph.D. Thesis submitted to National Dairy Research Institute (Deemed Univ.), Karnal.

Meena, G.S., Gupta, V.K., Khetra, Y., Raghu, H.V. and Khurana, S. 2014. Characterization of market Kheer Mohan. Indian J. Dairy Sci., 66(5): 380386.

Moulick, S., Ghatak, P. and Bandyopadhyay, A.K. 1996. A comparative study on the quality of market and laboratory-made kalakand. Indian J. Dairy Sci., 49(6): 406-412.

Murtaza, M.S., Sameen, A., Huma, N. and Hussain, F. 2017 Influence of Hydrocolloid Gums on Textural, Functional and Sensory Properties of Low Fat Cheddar Cheese from Buffalo Milk. Pak. J. Zool., 49(1).

Park, Y.W. and Haenlein, G.F. 2013. Milk and dairy products in human nutrition: production, composition and health. John Wiley \& Sons.

Patel, A.A., Patil, G.R., Garg, F.C. and Rajorhia, G.S. 1990. Texture of peda as measured by
Instron. In: brief communication of XXIII International Dairy Congress Montreal. 2: 527.

Patel, H.A. 1996. Comparative appraisal of quality of Peda manufactured and sold in selected cities of Gujarat state. M.Sc. Thesis submitted to Gujarat Agricultural University, Gujarat.

Patel, H.G., Prajapati, J.P., Solanky, M.J., Prajapati, P.S. and Soni, D. 2010. Characterization of Halvasan from market and a process of its manufacture. Indian J. Dairy Sci., 63(5): 376-380.

Patel, K.N., Patel, H.G., Prajapati, J.P. and Prajapati, P.S. 2012. Characterization of market Thabdi. Indian J. Dairy Sci., 65(2):122-128.

Rao, R.S. and Goyal, G.K. 2007 Effect of packaging and storage on the sensory quality of kalakand. Indian J. Dairy Sci., 60(2): 77-88.

Rasane, P. and Jha, A. 2012. Textural and sensory characteristics of market samples of peda manufactured in Varanasi city of India. $J$. Dairying Foods Home Sci., 31(4): 239-243.

Ray, P.R., Bandyopadhyay, A.K. and Ghatak, P.K. 2002. Comparative studies on quality of market available and laboratory made peda. Indian J. Dairy Sci., 55(2): 83-85.

Shete, S.M., Pawar, B.K., Choudhari, D.M. and Kamble, D.K. 2012. Quality of different types of burfi sold in Ahmednagar market. J. Dairying Foods Home Sci., 31(1): 5-8.

Singh, A., Singh, R.B. and Edward, J.C. 1975. Survey of the microbiological quality of burfi and pera in Allahabad market. Indian J. Dairy Sci., 2(9): 219-220.

Yam, K.L. and Papadakis, S. 2004. A simple digital imaging method for measuring and analyzing color of food surfaces. J. Food Eng., 61(1): 137-142.

\section{How to cite this article:}

Harin Sutariya, K. Jayaraj Rao, Ravi Chauhan, Nancy Talwar and Diwakar Mishra. 2017. Product Characterization of Thirattupal - A Traditional Sweet Product of Tamil Nadu, India. Int.J.Curr.Microbiol.App.Sci. 6(7): 2745-2755. doi: https://doi.org/10.20546/ijcmas.2017.607.385 